\title{
DE LA LÓGICA A LA RETÓRICA \\ La argumentación como estructura epistemológica de las ciencias sociales
}

\author{
GERM ÁN VARGAS GUILLÉN \\ Universidad Pedagógica Nacional \\ Bog otá, noviembre de 2002
}

Se trata de un arte esencialmente republicano. Hay que haberse habituado a tolerar las opiniones y puntos de vista más extraños e incluso a sentir un cierto placer en la contradicción; hay que escuchar con la misma satisfacción con que se habla y, en cuanto oyente, hay que estar en condiciones de apreciar poco más o menos el arte en cuestión.

Friedrich Nietzsche

Resumen: Artículo que busca fundamentar las ciencias sociales des de el punto de vista de la retórica; para ello se muestran los planteamientos que permiten el tránsito de la lógica a las estructuras argumentativas, con previo énfasis en las tes is centrales que definen la formalidad de la epistemología para estas ciencias. El giro de lógica a retórica requiere tanto la noción de auditorio universal como las relaciones entre la retórica y la hermenéutica; en fin, de lo que se trata es de dar curso al hecho de que las ciencias sociales vuelvan a su suelo nutricio: la ciudadanía y las posibilidades de que ella participe en la toma de decisiones mediante procesos deliberativos, de construcción del sentido social de lo público y de reconocimiento a la historicidad como fuente de los proyectos que pretenden a llevar a cabo las comunidades.

Sumario: Presentación. §1. La noción de epistemología. §2. El puesto de la argumentación en la decisión racional. §3. Retórica y hermenéutica. §4. ¿Tiene sentido hablar del auditorio univers al?

Palabras clave: argumentación, retórica, hemenéutica, decisión racional, ciencias sociales, epistemología.

Abstract: This article tries to give basis to the social sciences from the point of view of rethorics. To do that, statements that allow the transit from logic to argumentative structures are given. Previous emphasis is put to the central theses

\footnotetext{
*Este artículo lo desarrolló el autor-Profesor de la U. Pedagógica Nacional-, como parte de sus actividades en el grupo de investigación «Subjetividad y nuevas narrativas en ciencias sociales» de la Universidad Pedagógica Nacional.

${ }^{1}$ Curso de retórica. En: El libro del filósofo. Madrid, Ed. Taurus, 1974; págs. 125-126.
} 
that define the formality of epistemology for those sciences. The turn form logic to rethorics requires the notion of a "universal auditory", as well as, the relationships between rethorics and hermeneutics. In sum, the pupose is to support the fact that social sciences return to their nutritious ground: citizenship, and the possibility for it to participate in decision making processes through deliberation; the building of a social sense of the public affairs and the acknowledgement of historicity as the source of all projects of communitary nature.

\section{Presentación}

En Analíticos primeros 24a26, afirma Aristóteles:

De modo que la proposición de un razonamiento sin más será la afirmación o negación de algo unido a algo, (...) mientras que será demostrativa si es verdadera y obtenida a través de los supuestos de principios, y será dialéctica, para el que averigua, como pregunta <acerca> de la contradicción y, para el que argumenta, como asunción de lo aparente y lo plausible.

Con es ta teoría se distingue entre el ámbito de la inferencia válida, necesaria, o la estructura lógica del razonar y la argumentación o el uso retórico del lenguaje que recurre a los silogismos dialécticos, cuyo enlace no es necesario, sino tan sólo probable. Esta tes is -que relaciona y diferencia lógica y retórica- proviene de la doctrina de la lógica expuesta en Analíticos primeros. Sin embargo, ella muestra un enlace con los Tópicos y, a través de éstos, con el conjunto de la Retórica en este mismo autor.

La pregunta, pues, que queda planteada para las ciencias sociales es si ellas tienen que recurrir al uso de la inferencia necesaria, a lo que Aristóteles denominó el razonamiento verdadero -cuyo carácter es demostrativo-, o si, por el contrario, cuando se estudia lo social, los fenómenos de la vida comunitaria, se mantiene abierta la perspectiva de la contradicción, es decir, se recurre al proyecto argumentativo tendiente a as umir tanto lo aparente como lo plausible, en términos de construir la razonabilidad. En último término, la cuestión que se hace visible es la diferencia entre lo racional demostrativo y lo razonable, plausible, que muestra y construye el "lugar" (topos, topoi) de lo preferible.

En su debate con Hempel, Paul Ricoeur ${ }^{2}$ señaló que:

Todo acontecimiento singular puede deducirse de dos premisas. La primera describe las condiciones iniciales: acontecimiento precedente, condición previa, etc. La segunda enuncia una regularidad, una hipótesis universal que, una vez verificada, pasa a llamarse «ley». Si estas dos premisas se formulan convenientemente, el acontecimiento

\footnotetext{
${ }^{2}$ Paul Ricoeur. Para una teoría del discurso narrativo. En: Historia y narratividad, Barcelona, Paidós, 1999, págs. 85 á 89.
} 
considerado puede deducirse lógicamente. En ese caso decimos que lo hemos explicado (pág. 86).

Queda, as í, abierto el problema de si las ciencias sociales alcanzan a explicar, en el sentido de la lógica, o se restringen a realizar la tarea interpretativa, en el sentido hermenéutico (cf. infra, § 3); es decir, no se puede sobreentender que estas ciencias o tienen que estructurarse en modo exclusivo según las convenciones lógicas -orientándolas, con ello, a la predicción y el control en el sentido positivista-, o de manera única tienen que darse a la tarea de discutir lo público -función, más bien, propia del periodismo, la novela y la etnografía, según la propuesta de R. Rorty ${ }^{3}$.

Si las ciencias sociales adoptan el modelo explicativo, se someten al modelo causal; ello mismo les permitiría tener algún nivel de pronóstico o de previsión del futuro. En ese caso, de diversas maneras podrían hacer uso de la lógica para predecir cómo se va a realizar la experiencia y cuál será el desarrollo de los hechos por venir.

Como consecuencia de las observaciones precedentes, se puede circunscribir el anális is aquí en los siguientes téminos: si las ciencias sociales se liberan del sometimiento a los cánones de la lógica como único fundamento para su desarrollo, entonces se liberan -por igual- de las ciencias naturales en la construcción de su discurso.

Así circunscrita la pregunta, empieza a tener un papel en el análisis el problema retórico, es decir, el de las condiciones para persuadir un auditorio. Se tiene una vía alterna para las ciencias sociales si, en cambio de la búsqueda la inferencia válida, se busca cons tituir (retórica) y comprender (hemenéutica) el sentido.

¿En qué queda, entonces, el proyecto de la epistemología para las ciencias sociales, si se da el giro de lógica a retórica; esto es, de inferencia a argumentación?, ¿qué relaciones se tienen que establecer entre retórica y hemenéutica en las ciencias sociales?, ¿cómo se valida el conocimiento en la investigación social bajo este «giro»? Son las cuestiones que se debaten enseguida.

\section{La noción de epistemología}

Perelman ha reivindicado la retórica como el modelo propio de una "lógica de lo preferible» que debe decidir en materia de las opciones éticas y políticas y que ha de ser concebida, por lo tanto, con mayor extensión que la lógica de las ciencias.

Quint ín Racionero ${ }^{4}$

\footnotetext{
${ }^{3}$ Rorty, Richard. Contingencia, ironía y solidaridad. Barcelona, Ed. Paidós, 1991; pág. 112. Cf. Vargas Guillén, Germán. Pensar sobre nosotros mismos. Bogotá, Sociedad de San Pablo, 2002; pág. 412.

${ }^{4}$ Racionero, Quintín. Introducción. En: Aristóteles. Retórica. Madrid, Ed. Gredos, 1999; pág. 9. 
En El imperio retórico ${ }^{5}$ Chaïm Perelman recuerda que:

Sócrates prepara el camino a la intuición de la verdad. Cuando la percibe, el filósofo podrá servirse de la técnica retórica para comunicarla y hacerla admitir a su auditorio. La retórica digna del filósofo es la que podrá persuadir a los dioses mismos, pues ella busca la adhesión a tesis verdaderas y no a simples opiniones (Ed. cit.; pág. 202).

Con este análisis Perelman retorna a Platón (Fedro, 273e); ésta es una primera vía para caracterizar la retórica. Se supone en ella que la verdad filosófica tiene que ser aquello que por sí mismo persuada.

Al lado de esta estructura -la de la retórica expositiva de la verdad-podría pervivir otra retórica: la que se olvida de la verdad, la que procura que se adhiera el auditorio por efecto del uso del lenguaje, la del encanto de la palabra que, recurriendo a la adulación -a lo aparente-, conmueve y hace que los sentimientos de los sujetos se acerquen a lo que pretende el orador.

Esta segunda vía: la de la seducción, que ya para la época de Platón era tradicional, fue combatida por éste; es la que ha llevado a considerar que el objeto de la retórica es el ornato, tan sólo un conjunto de figuras y técnicas -vacías de contenido, carentes de verdad-.

Ahora bien, en la manera como se considera el sentido y la trayectoria de la retórica bajo el supuesto platónico, con posterioridad reivindicado bajo el título de evidencia en la concepción cartesiana, hay una tercera vía -que renuncia a la «verdad» como fundamento inconcuso- para pensar el sentido del despliegue de la razonabilidad y, dentro de ella, la manera como tienen que operar las ciencias sociales. Se trata de aislar el concepto protofundante de la "verdad», para dar con una teoría de la construcción social del mutuo entendimiento. La tes is de Ch. Perelman es que:

En lugar de buscar una primera verdad necesaria y evidente de la cual estaría suspendido todo nuestro saber, arreglemos nues tra filosofía en función de una visión, donde los hombres y las sociedades humanas en interacción, los únicos responsables de su cultura, de sus instituciones y de su porvenir, son los que se esfuerzan por elaborar sistemas racionales imperfectos, pero perfectibles.

El dominio por excelencia de la argumentación, de la dialéctica y de la retórica, es aquel en el que intervienen valores (Íd., pág. 209).

El análisis se orienta, así, en el sentido de caracterizar cómo hay un objeto de investigación propio de las ciencias sociales que no compete al uso del enlace

${ }^{5}$ Perelman, Chaïm. El imperio retórico. Bogotá, Ed. Norma, 1997. (Traducción: Adolfo León Gómez Giraldo). 
necesario entre premisas y conclusiones o a las distintas formas de la inferencia válida según el estilo tradicional y canónico de la lógica. Este objeto son los valores. Porque ellos son la "cosa misma" que investigan las ciencias sociales, se configura para éstas el campo de lo preferible y, como consecuencia, las estrategias de persuasión se convierten en una estructura metódica que ordena o puede ordenar el proceso tendiente a producir conocimiento en este contexto.

Si se recurre de nuevo al horizonte platónico y cartesiano, se hablaría de la urgencia de habilitar lo que Perelman ha identificado con el título de «auditorio universal».

(...) la eficacia de un argumento es relativa al auditorio, es imposible apreciarla fuera de la referencia al auditorio al cual se presenta. Al contrario, la validez es relativa a un auditorio competente, la mayoría de las veces al auditorio universal (Íd.; pág. 185).

La idea de un "auditorio universal» se puede resumir así: un argumento es persuasivo si vale para uno y vale para todos, o, como también se ha señalado ya en la interpretación perelmaniana de Platón, la retórica filosófica es aquella que convencerá a los mismos dioses.

El «auditorio universal» es del tipo - de auditorio- al que se pretende que está orientada la retórica filosófica. Sin embargo el mismo Perelman ha mostrado que el objeto de la persuasión, o el camino para ella, tiene que restringuirse. Al final del El imperio retórico, observa que:

(...) todo discurso que no pretende una validez impers onal tiene que ver con la retórica. Desde que una comunicación tiende a influir sobre una o varias personas, a orientar su pensamiento, a excitar o calmar las emociones, a dirigir una acción, ella es del dominio del la retórica (Íd.; pág. 211).

En fin, pues, la retórica es una teoría de la comunicación persuasiva, es el intento de hacer que los intereses y las acciones motivadas por ellos sean encaminados a construir una socialidad común. Sin embargo, uno de los elementos de este modo de entender el sentido y el horizonte de la retórica radica en que, para que ella pueda ser realizada, implica el reconocimiento del otro, de aquellos a quienes el orador "quiere influir con su argumentación". " En este horizonte, querer convencer a alguien implica modestia por parte de quien argumenta. Se asume que és te no expresa un dogma de fe, tampoco dispone de manera total y absoluta de la autoridad para que sus argumentos resulten indiscutibles o lleven con inmediatez a la convicción. Por su naturaleza, argumentar impone el reconocimiento del otro;

\footnotetext{
${ }_{7}^{6}$ Fedro, 273e; Perelman, Ch., ob. cit., pág. 196.

${ }^{7}$ Perelman, Chaïm; Olbrechts-Tyteca, Lucía. Tratado de la argumentación. La nueva retórica. Madrid, Editorial Gredos, 1989, pág. 55.
} 
este proceso sólo es eficaz en la medida en que se opera la mentada inclusión. Así lo indican Perelman y Olbrechchts-Tyteca al as everar:

El orador admite que debe persuadir al interlocutor, pensar en los argumentos que pueden influir en él, preocuparse por él, interesarse por su estado de ánimo (Íd., pág. 51).

De este modo, asumirse como «dialogante» («palabra en diálogo»; bien como auditorio, bien como orador) implica valorar el punto de vista de los interlocutores ${ }^{8}$. En el desarrollo de la argumentación se busca el consentimiento y concurso mental (psíquico, espiritual, deliberativo) del otro; a éste se lo reconoce con capacidad para discutir, para presentar argumentos diversos y rivales; es decir, la retórica aparece como una posible estructura de las ciencias sociales porque se parte del supuesto de que lo social es, en efecto, social; o sea, no es dominio del que presenta las tesis al auditorio, sino que tal dominio lo es de los interlocutores, que están insertos en la experiencia y en la vida de la sociedad.

Si se mira, entonces, un primer aspecto, a saber, cuál es el alcance del título epistemología; se encuentra que ella radica en definir objeto de estudio, método y procesos de validación del conocimiento que aspira al status de ciencia.

- El objeto de estudio de las ciencias sociales es el proceso de persuasión sobre unos valores que se juzgan preferibles ${ }^{9}$.

- En el orden del método, la inclusión del otro, su reconocimiento como interlocutor válido.

- En el orden de la validez el sentido de és ta radica en que se encuentre unidad de acción, o confluencia de voluntades; y esto, por supuesto, implica un enraizamiento en la experiencia social cotidiana que deshegemoniza el punto de vista unilateral del científico social como un arconte o como un sacerdote, al tenor de los proyectos de E. Hussen y A. Comte.

\section{La decisión racional}

El lenguaje no es sólo un medio de comunicación, también es un instrumento para influir en los hombres, un medio de persuasión. (...).

Los valores admitidos por el auditorio, el prestigio del orador, hasta el lenguaje empleado, todos estos elementos están en constante interacción cuando se trata de conseguir la adhesión de los individuos.

Ch. Perelman \& L. Olbrechts-Tyteca ${ }^{10}$

\footnotetext{
${ }^{8}$ Nietzsche, Friedrich. Ob. cit.; págs. 125-126.

${ }^{9}$ Tiene sentido pensar en la diferencia entre valores de verdad y valores éticos. Mientras los primeros pareœn ser los que estructuran las ciencias naturales y las formales, según la concepción de referente debida a Gottlob Frege; los segundos son la cosa misma de que se ocupan las ciencias sociales, en cuanto ciencias de la discusión, siguiendo la vertiente propuesta por Ch. Perelman.

${ }^{10}$ Perelman, Ch.; Olbrechts-Tyteca; Ed. cit., pág. 216. 
Mientras la doctrina de la verdad implica que ésta se impone a todo aquel que se enfrente con ella ${ }^{11}$, la doctrina de la persuasión parte del supuesto de que ninguno de los interlocutores se halla en el punto final al que tiene que arribar todo razonamiento. Esta doctrina también supone que el proceso argumentativo encamina a los interlocutores a comprender, en diversas direcciones:

- Comprender los fenómenos sobre los cuales el orador está argum entando.

- Comprender el punto de vista del interlocutor.

- Comprender la adecuación o preferibilidad de una manera de interpretar el sentido de la acción para que haya consenso o para que se pueda construir la estructura social de la acción.

- Hacerse comprender, como orador, por los otros -por la audiencia-.

La elección racional cons iste en un cambio de actitud que gira del punto vis ta de la verdad como postulado a la persuasión como camino para hallar posibles acuerdos. Ésta, por tanto, construye de manera compartida formas de interpretar el mundo social que a su vez permiten el despliegue colectivo del comprender, a partir del reconocimiento mutuo de intereses, y de su posible validez, para el desarrollo de la acción estratégica; es decir, impone una pragmática del discurso en donde las posibilidades de interactuar dependen, no de una visión de la verdad, sino de la pluralidad de perspectivas desde las que puede ser interpretado el sentido de lo público, el despliegue de la construcción política y el horizonte de convivencia, desde los dis tintos sujetos que intervienen en la acción compartida.

Perelman y Olbrechts-Tyteca indicaron:

Quien exija de una argumentación que proporcione pruebas apremiantes, pruebas demostrativas, y no se contente con menos para aceptar una tesis, desconoce, igual que el fanático, el carácter mismo del proceso argumentativo. Este, ya que tiende precisamente a justificar las opciones, no puede ofrecer justificaciones que muestren que no hay elección posible, sino que una única solución se les presenta a quienes examinan el problema.

A no ser siempre totalmente necesaria la prueba retórica, quien se identifique con las conclusiones de una argumentación lo hace mediante un acto que lo compromete y del que es responsable (ĺd.; pág. 116).

Para Perelman y Olbrecht-Tyteca la diferencia entre el punto de vista lógico y el punto de vista retórico radica en que en el primero hay posibilidad de actuar no sólo como un dogmático, sino también como un fanático -si se cambia del uso de

\footnotetext{
${ }^{11}$ Recordando, así, la premisa según la cual cuando dos o más sabios se encuentran en discordia, uno de ellos debe estar equivocado y, por regla general, ambos, pues si alguno estuviera en posesión de la verdad podría convencer al otro, según ya lo enseñó Descartes en las Reglas para la dirección del espíritu (AT, X, 363).
} 
la lógica del plano de las ciencias naturales a su aplicación en el contexto de la investigación social-.

Dogmatismo y fanatismo son dos cualidades puestas en cuestión en la perspectiva retórica. Al argumentar se asume que, en efecto, hay intereses y que los sujetos pueden hacer visible el horizonte desde el cual los están sorteando; que, si bien valen para sí, pueden o no valer para el conjunto de los interlocutores y, en ese sentido, para ese ám bito de la sociedad en el cual se están jugando.

Por eso, pues, se debe destacar el punto que ha analizado Paul Ricoeur ${ }^{12}$ cuando, cita a Nietzsche para señalar que "la elocuencia es republicana"13. Así, pues, el recurso a la retórica permite considerar que la palabra es un arma destinada a influir en el pueblo, ante el tribunal, en la as amblea pública; es un arma para el elogio y el panegírico, en fin, es "un ama llamada a dar la victoria en las luchas en que lo decisivo es el discurso" (Ricoeur, ĺd.).

A este mismo análisis se le debe conceder validez cuando se expresa en los siguientes téminos:

La técnica basada en el conocimiento de las causas que engendran los efectos de la persuasión da un poder temible al que la domina perfectamente: el poder de disponer de las palabras sin las cosas y de disponer de los hombres disponiendo de las palabras (Íd.; pág. 19).

Asumir, entonces, el valor de la retórica es reconocer que hay un poder que radica en la posibilidad deliberatoria; que ésta es capaz de llevar a que los distintos interlocutores se adhieran desde la racionalidad, apelando a lo razonable, a puntos de vista; que esta adhesión no sea indefinida en el tiempo-eterna-, sino que im plique un acuerdo sujeto a tiempo y espacio.

La pregunta que pone en movimiento la investigación es la siguiente: ¿qué es persuadir? ¿En qué se distingue la persuasión de la adulación, de la seducción, de la amenaza, es decir, de las formas más sutiles de la violencia? ¿Qué significa influir mediante el discurso? (Íd., pág. 20).

El objeto de investigación en materia de retórica, como queda visto, se mueve en simultáneo dentro de varios campos: de un lado hay un estudio exclusivo de lo lingüístico en el que se trata de establecer cómo se usa el lenguaje, cómo tiene efectos prácticos en la toma de decisiones y en el curso de la vida de los sujetos; pero, también, hay aquí un componente psicológico puesto que se debe hacer claridad sobre las pasiones y los motivos de la acción que están inscritos en la naturaleza de los sujetos; se da, del mismo modo, una dimensión política porque

\footnotetext{
${ }^{12}$ Ricoeur, Paul. La metáfora viva. Madrid, Ediciones Cristiandad, 1980; pág. 18.

${ }^{13}$ Nietzsche, F. Ed. cit. (Vid. supra, nota 7).
} 
de lo que se trata, in concreto, es de construir el desenvolvimiento o el horizonte de la pólis.

Así, pues, el recurso a lo verosímil tiene tres dimensiones: la lingüística, la psicológica y la política. Hay, o puede haber, en todas ellas el interés de establecer el valor filosófico del proceso. Esta validación consiste en que, no obstante las diversas direcciones posibles para la práctica, los intereses y las perspectivas individuales, también se puede caminar en la dirección de la búsqueda de la verdad; y sin embargo

El tipo de prueba que conviene a la elocuencia no es lo necesario sino lo verosímil, pues las cosas humanas, sobre las que deliberan y deciden los tribunales y asambleas, no son susceptibles de la necesidad o constricción intelectual que exigen la geometría y la filos ofía fundamental (Íd., pág. 21).

De lo que se trata, pues, es de hacer cada vez más explícito el asunto de la decisión racional. Ésta tiene todos los componentes señalados, pero se encamina a dar un fundamento al decurso político de la praxis, a hallar el fundamento de ésta, aun cuando éste no se convierta en una forma o estructura para intervenir sobre los hechos, esto es, aun cuando no se traduzca en "acción estratégica".

La decisión racional tiene que ver, entonces, con elevar al ámbito del concepto las formas en que se comprende, se interpreta y se propone el horizonte de los sujetos en el mundo de la vida social y político. Puede estar ordenado a la acción estratégica o puede estarlo al logro de su fundamento. De cualquier manera, siempre el problema deliberativo, que conduce la decisión racional, es el de encontrar motivos y razones que, en efecto son circunstanciales, dependen de la comunidad donde se elaboran, pero que valen al menos para esa comunidad.

\section{Retórica y hermenéutica}

(...) la retórica denota la lingüisticidad realmente universal que subyace esencialmente en lo hemenéutico en el otro sentido, $y$ representa algo así como el positivo respecto al negativo del arte de la interpretación lingüística. Las relaciones entre retórica y hemenéutica (...) se pueden ampliar en muchas direcciones (...). La lingüisticidad se inserta en definitiva tan profundamente en la socialidad del ser humano que el derecho y los límites de la problemática hemenéutica tienen que ocupar al teórico de las ciencias sociales.

Hans-Georg Gadamer ${ }^{14}$

\footnotetext{
${ }^{14}$ Gadamer, Hans-Georg. Verdad y método. Salamanca, Ed. Sígueme; 1992. Tomo II, págs. 226-
} 227. 
En su polémica con Jürgen Habermas, Gadamer procura mostrar el nexo existente entre retórica y hermenéutica. Es evidente que una y otra disciplinas, con sus respectivas posibilidades, tienen su unión por el lenguaje. Sin embargo, en una y otra el uso difiere. Mientras en el campo retórico, en sus bases, el lenguaje se vincula al auditorio en un momento del tiempo -que se puede considerar como un uso sincrónico del lenguaje-, la hermenéutica denota la historicidad $-\mathrm{y}$, por ello mismo, hace del lenguaje un uso diacrónico-.

Ahora bien, ¿pueden las ciencias sociales declarar a una u otra dimensión como espúrea, o, por el contrario, ambas integran y constituyen el proyecto de construcción relativo al desarrollo de una razonabilidad e, incluso, de una racionalidad civil?

\section{Para Gadamer}

No habría oradores ni retórica sino existieran el acuerdo y el consenso como soporte de las relaciones humanas; no habría una tarea hermenéutica si no estuviera roto el consenso de los que «son un diálogo» y no hubiera que buscar el consenso. La combinación con la retórica es, pues, idónea para deshacer la apariencia de que la hermenéutica se ciñe a la tradición estético-humanista y de que la filosofía hemenéutica se refiere a un mundo del "sentido" contrapuesto al mundo del ser «real» yque se prolonga en la «tradición cultural».

En consonancia con su universalidad, el enfoque hemenéutico debe también considerarse para la lógica de las ciencias sociales (Íd.; pág. 230).

El horizonte de la retórica está delimitado al tiempo y espacio en que se obtiene un acuerdo; pero éste, que se manifiesta como consenso, es objeto de desarrollo en el tiempo, en otros momentos del mismo, en otras circunstancias, es decir, en el devenir del mundo social. Si se obtiene, entonces, el consenso, és te tiene que ser objeto de interpretación en la dinámica histórica. El problema, tal como está planteado, indica que se requiere un nexo íntimo entre retórica y hemenéutica, entre sincronía y diacronía, entre momento y desenvolvimiento his tóricos.

Las ciencias sociales tienen que hacer permanente recurso a los dos momentos o modos de construcción, sincrónico y diacrónico: en el primero para que la ciudadanía se exprese hasta obtener consenso; en el segundo para que ella juzgue la validez del acuerdo y reoriente el sentido de sus acciones. Como en el acuerdo no queda inscrita una verdad, sino un horizonte de sentido, la hermenéutica es un camino por el cual lo intencionado se va impletando o llenando de contenido (de verdad como experiencia, de desacuerdo, de perspectivas).

La retórica se puede comprender como un dispositivo para poner en funcionamiento el proceso deliberativo. Sin embargo, ella no detiene el acontecer 
histórico, pues éste tiene la posibilidad de hacer manifiesto el desacuerdo; el cual, a su turno, amplía el espectro hemenéutico al hacer posible distintos cursos para realizar o implementar su estilo público en políticas, en formas de acción, en estrategias adminis trativas incluso, de lo que se ha convenido o acordado.

Uno de los tópicos adarados por Habemas, en el texto que discute Gadamer en la mentada controversia, es que:

(...) peculiar resultado de la comprensión hermenéutica en relación con la apropiación lograda de tradiciones es también someter a reflexión y hacer transparentes en su génes is a partir de la tradición los prejuicios que lleva aparejada la situación de partida del intérprete ${ }^{15}$.

Este análisis hace visible que hay entrelazamiento entre sincronía y diacronía, es decir, entre punto de vista del intérprete ubicado en el presente, que por supuesto se encuentra ya, de suyo, en una comprensión hemenéutica del pasado en perspectiva del futuro.

En el punto de vista para la interlocución en el proceso tendiente a la búsqueda de consenso- el sujeto delibera en el presente -en sincronía- y al mismo tiempo enraiza su pers pectiva hermenéutica en el aquí y en el ahora (hic et nunc), con las tradiciones y los prejuicios -en diacronía, en historicidad-.

Así se hace visible que hay nexo entre retórica y hermenéutica; que, en su fundamento, las ciencias sociales no pueden hacer uso de uno de estos dos postulados teórico-metodológicos como un recurso unilateral.

\section{4. ¿Tiene sentido hablar del auditorio universal?}

El auditorio de élite sólo encama al auditorio universal para aquellos que le reconocen este papel de vanguardia y de modelo. Para los demás, en cambio, no constituirá más que un auditorio particular. El estatuto de un auditorio varía según las consideraciones que se sustentan.

\section{Ch. Perelman y L. Olbrechts-Tyteca ${ }^{16}$}

La búsqueda de argumentos que persuadieran a los dioses mismos impone, como se ha mostrado, la noción de «auditorio universal». No obstante, se cuestiona esta idea -de «auditorio universal»-.

Es normal que los espíritus competentes e ilustrados se identifiquen con la comunidad científica o con la comunidad filosófica. La cuestión que queda de

\footnotetext{
${ }^{15}$ Habemas, Jürgen La lógica de las ciencias sociales. Madrid, Editorial Técnos, 1990, pág. 247.

${ }^{16}$ Tratado de la argumentación, Ed. cit., pág. 76.
} 
manifiesto es si se puede restringir a éstos el decidir sobre los asuntos relacionados con lo público, con lo social, con el sentido de lo comunitario, con el horizonte histórico de la convivencia.

El problema es que para ser parte de un «auditorio universal» o de una comunidad con alta especialización, por ejemplo filosófica, se impone que se haya:

- Tenido entrenamiento,

- Cumplido las exigencias del grupo especializado,

- Tenido maestro,

- Sufrido el proceso de iniciación en una disciplina determinada.

En fin de cuentas, se espera que los sujetos de la deliberación:

- Conozcan las reglas y las técnicas de participación dentro de ella,

- Dominen las nociones específicas,

- Conozcan qué es todo lo aceptado en la disciplina,

- Puedan jugar dentro de las reglas con las que se critican los resultados dentro de cada disciplina particular ${ }^{17}$.

Para ser reconocido como un espíritu competente e ilustrado, en cierto modo, se requiere que el espíritu se haya domesticado has ta que pueda actuar con las reglas de juego de la comunidad que, a símisma, se reconoce como especialis ta y que en el entorno social, entonces, se ha impuesto como el «lugan» en el que se valida el conocimiento en una disciplina.

Lo que queda interrogado es si el dominio de lo social se puede entregar a una comunidad de expertos y si es te juego puede desplazar la decisión comunitaria al poder de unos sujetos que se han sometido a unas reglas que, a su vez, han sido construidas para definir el «lugar» de la verdad; al final, en ese juego, los expertos se autolegitiman.

En el auditorio todo parece funcionar cuando se tienen "cosas admitidas" y todas ellas "pueden influir en las reacciones" (Íd). Por tanto, para un auditorio especializado, estas cuasicreencias "será[n] el corpus del saber reconocido por los partidarios de una dis ciplina científica" (pág. 191).

El problema queda así planteado: si el auditorio universal es la comunidad científica de una disciplina, las ciencias sociales han renunciado a ser sociales; si los auditorios son particulares, son tópicos, es decir, circunstanciales, entonces ya no son ciencias. El predicamento es si, por la es trategia de la lógica o por la de la retórica, las ciencias -sean de lo social, de lo formal, de lo natural- pueden renunciar a tener postulados que valen para uno y que valen para todos. Si ese

\footnotetext{
${ }^{17}$ Cf. Perelman, Ch.; Olbrecht-Tyteca, L. Tratado de la argumentación; Ed. cit., págs. 169-170.
} 
fuera el caso de las sociales, ¿continuarían siendo ciencias? Si renunciaran a ese postulado, quedaría por discutir la opinión de R. Rorty según la cual esta actividad se lleva a cabo con mayor pertinencia en el periodismo y en la novela (cf. supra Presentación, nota 2).

\section{BIBLIOGRAFÍA}

Aris tóteles. Retórica. Madrid, Ed. Gredos, 1999; 626 págs.

Aristóteles. Tratados de lógica (Órganon) II. Madrid, Ed. Gredos (BCG), 1995; 460 págs.

Gadamer, Hans-Georg. Verdad y método. Salamanca, Ed. Sígueme; 1984. Tomos I yll.

Habemas, Jürgen. La lógica de las ciencias sociales. Madrid, Editorial Tecnos, 1990, 506 págs.

Nietzsche, Friedrich. Retórica y lenguaje. En: El libro del filósofo. Madrid, Ed. Taurus, 1974, págs. 123 á 189.

Perelman, Chaïm. El imperio retórico. Bogotá, Ed. Norma, 1997, 214 págs.

Perelman, Chaïm; Olbrechts-Tyteca, Lucía. Tratado de la argumentación. La nueva retórica. Madrid, Editorial Gredos, 1989, 847 págs.

Ricoeur, Paul. Historia y narratividad, Barcelona, Paidós, 1999, 230 págs.

Ricoeur, Paul. La metáfora viva. Madrid, Ediciones Cristiandad, 1980; 437 págs.

Rorty, Richard. Contingencia, ironía y solidaridad. Barcelona, Ed. Paidós, 1991; 222 págs.

Vargas Guillén, Germán. Pensar sobre nosotros mismos. Bogotá, Sociedad de San Pablo, 2002; 446 págs. 